To cite this article: Demir R, Taşpınar A. The role of the midwife in the development of maternal and child health services in the pandemic period. Turk J Womens Health Neanotol 2021;3(4): 104-110

- Derleme

\title{
Pandemi Döneminde Ana Çocuk Sağlığı Hizmetlerinin Geliştirilmesinde Ebenin Rolü
}

\section{The Role of the Midwife in the Development of Maternal and Child Health Services in the Pandemic Period}

\author{
Rukiye Demir*1 $\square$, Ayten Taşpınar ${ }^{2}$ \\ ${ }^{1}$ Tekirdağ İsmail Fehmi Cumalıoğlu Şehir Hastanesi, Tekirdağ, Turkey \\ ${ }^{2}$ Aydın Adnan Menderes Üniversitesi, Sağlık Bilimleri Fakültesi, Ebelik Bölümü
}

\section{Öz}

Ana çocuk sağlığını etkileyen birçok önemli faktör olmakla birlikte bunlara günümüzde yaşadığımız koronavirüs pandemisini de ekleyebiliriz. Küresel olarak bu pandemi nedeniyle yaşanan ekonomik ve sosyal değişimler, bilim ve teknoloji alanındaki ilerlemeler ülkelerin sağlık politikalarına yön vermiş, beraberinde özellikle ana çocuk sağlığının geliştirilmesi ve bakım hizmetlerinin verilmesi süreçlerinde aktif rol alan ebelerin rol ve sorumluluklarında bazı değişimlerin yaşanmasına neden olmuştur. Ana çocuk sağlığının gelişmesi önce aile, daha sonra toplum sağ Iığının gelişmesi demektir. Bu nedenle pandeminin ana çocuk sağığına etkisinin değerlendirilmesi, olumsuz etkilerinin belirlenerek, bu etkileri iyileştirme çabalarına hizmet edebilecek önlemlerin alınması ve pandemi döneminde ana çocuk sağlığının geliştirilmesinde ebelerin rolünü bilmek oldukça önemlidir. Bu derlemenin amacı; pandemi döneminde ana çocuk sağlığı hizmetlerinin geliştirilmesinde ebenin rolünü literatür doğrultusunda incelemektir.

Anahtar Kelimeler: Ana çocuk sağlığı; ebe; koronavirüs; pandemi; rol

Corresponding Author *: Rukiye Demir, Tekirdağ İsmail Fehmi Cumalığlu Şehir Hastanesi, Tekirdağ.

e-posta: rukiye_kiymik@hotmail.com

ORCID: 0000-0003-4649-6403

DOI: $10.46969 /$ ezh.975772

Geliş tarihi: 28.07.2021

Kabul tarihi: 17.12.2021 


\begin{abstract}
While many essential factors affect maternal and child health, we can also add the coronavirus pandemic that deeply affects maternal and child health. The economic and social changes experienced globally due to this pandemic, advances in science and technology have shaped the health policies of countries and have led to some changes in the roles and responsibilities of midwives, who take an active role, especially in the development of maternal and child health and the provision of care services. The result of maternal and child health means developing family health first and then community health. For this reason, it is vital to evaluate the impact of the pandemic on maternal and child health, determine its adverse effects, take measures that can serve to improve these effects, and know the role of midwives in improving maternal and child health during the pandemic period. This review aims to investigate the midwife's role in the development of maternal and child health services during the pandemic period.
\end{abstract}

Keywords: Maternal and child health; midwife; coronavirüs; pandemic; role

\section{Giriş}

Ana çocuk sağığı hizmetleri; evli ya da bekâr 15-49 yaşları arasındaki bütün kadınlara ve yaşına bakılmaksızın gebelere, doğum yapanlara ve lohusalara götürülen hizmetlerdir $(1,2)$. $\mathrm{Bu}$ hizmetlerin amacl; gebe, bebek, loğusa tespitlerinin ve izlemlerinin hazırlanan protokollere ve kriterlere uygun olarak yapılmasını sağlamak, anne ve bebek ölümlerini azaltmak ve toplumun önemli bir kesimini oluşturan kadın, anne, bebek ve çocukların dolayısıyla toplumun sağlığını yükseltmektir (36). Doğurganlığın yüksek olduğu, annenin gebelik ve doğumda yeterli bakımı alamadığı, kendi ve çocuğunun bakımıyla ilgili gerekli bilgiye sahip olamadığı durumlarda ana çocuk sağlığının iyi olması beklenemez. Bu bağlamda ana çocuk sağlığının yükseltilmesi ve geliştirilmesi, anne ve bebek ölümlerinin önlenebilmesi için gebeliğin ilk dönemlerinden başlayarak periyodik olarak kadının izlenmesi, sağıı ve danışmanlık hizmetlerinin eksiksiz verilmesi gerekir $(7,8)$. Dünyada her yıl 528,000 anne ölümünün gerçekleştiği tahmin edilmektedir. Bu ölümlerin sadece \%1'i gelişmiş ülkelerde, geri kalan \%99'u ise gelişmekte olan ülkelerde meydana gelmekte olup, bu ölümlerin \%90’ı önlenebilir nedenlerdir. Anne ölümlerinin seviyesi, sağlık hizmetlerinin sağlanması ve kalitesi bakımından çok boyutlu bir kalkınma göstergesidir (9).

Ana çocuk sağlığının korunması ve yükseltilmesiyle ilgili çalışmalar devam ederken Çin'in Hubei eyaletine bağı Wuhan kentinde ortaya çıkan koronavirüs (COVID-19) enfeksiyonu bütün dünyayı etkisi altına almış ve bir salgına dönüşmüştür $(5,9)$. Her ülke salgından farklı biçimde etkilenmiş olsa da salgının özellikle ana çocuk sağlığı üzerindeki etkileri pek çok ülkede benzer özellikler taşımaktadır $(10,11,13)$. Birleşmiş Milletler tarafından sunulan "The Impact of COVID-19 on Women" başlıklı raporda pandemi nedeniyle kadınların çocuklarına ya da yakınlarına verdikleri bakım yükünün oldukça arttığı, kadın ve çocukların yüksek riskli popülasyonlardan biri olarak kabul edilebileceği vurgulanmıştır (14). DSÖ (Dünya Sağlık Örgütü), COVID-19 pandemisi nedeniyle erkeklerin kadınlara oranla daha fazla öldüğünü (kadınlarda \%2,8, erkeklerde \%4,8) ancak bu süreçte kadınların sağlığının erkeklere göre daha olumsuz etkilendiğini ve çocuklarında pandeminin bu olumsuz etkilerinden nasibini aldığı bildirmiştir (9).

Pandemi nedeniyle yaşanan ekonomik ve sosyal değişimler ile bilim ve teknolojideki ilerlemeler ülkelerin sağlık politikalarına yön vermiş, beraberinde sağlık çalışanlarının rol ve sorumluluklarında bazı değişimlerin yaşanmasına neden olmuştur $(15,16)$. Bu bağlamda ana çocuk sağlığının geliştirilmesi, korunması, gerektiğinde tanı ve tedavisinin sağlanması ve rehabilitasyon hizmetlerinin verilmesi süreçlerinde aktif rol alan ebelerin de rol ve sorumluluklarında bazı değişimler yaşanmıştır $(7,8)$. Ana çocuk sağlığının gelişmesi önce aile sonra toplum sağlığının gelişmesi demektir; bu nedenle COVID-19 pandemisinin ana çocuk sağlığına etkisinin değerlendirilmesi, olumsuz etkilerinin belirlenerek, bu etkileri iyileştirme çabalarına hizmet edebilecek önlemlerin alınması ve bu konudaki ebelerin rolünü bilmek oldukça önemlidir $(2,5,7,16)$. Bu derlemenin amacı; pandemi döneminde ana çocuk sağlığı hizmetlerinin geliştirilmesinde ebenin rolünün güncel literatürdeki bulgular ışığında değerlendirilmesidir.

\section{Pandemi Döneminde Ana Çocuk Sağlığı Hizmetlerinin Geliştirilmesi}

Son yıllarda ana çocuk sağlığı hizmetlerine verilen önem, 
ülke genelinde yaygın ve etkili hizmet sunumuna yönelik çabalar ve çalışmalar sonucunda bu alanda önemli mesafeler kaydedilmiş, anne ve bebek ölüm hızlarında önemli düşüş, ana çocuk sağlığında birçok ilerlemeler elde edilmiştir (1719). Fakat günümüzde küresel olarak pandemi nedeniyle yaşanan ekonomik, sosyal ve siyasal yaşamdaki değişimler ile bilim ve teknolojideki ilerlemeler ülkelerin sağlık politikalarına yön vermiş, birçok alanda değişimlerin yaşanmasına neden olmuş, ana çocuk sağlığı ve gelişimi pandemiden olumsuz olarak etkilenmiştir (5,20-22). Bu etkilerin en aza indirilmesi, ana ve çocuk sağlığının gelişiminin sağlanması nedeniyle ülkeler çeşitli birtakım önlemler almış, politikalar ve stratejiler geliştirmiş, bu stratejileri uygulamaya başlamıştır. Pandemi kapsamında alınan önlemler, yerinde ve zamanında yapılan tüm girişimler, ana çocuk sağıı̆ının korunmasına, güçlendirilmesine, geliştirilmesine hizmet edecek ve tüm dünyada kadınların ve çocukların daha eşit ve ulaşılabilir bir sağlık hizmeti almasına katkı sağlayacaktır (23-25).

\subsection{Pandemi Döneminde Ana Çocuk Sağlığı Hizmetlerinin Geliştirilmesinde Ebenin Rolü}

Koronavirüs pandemisinde gebeler, yeni doğum yapmış kadınlar, yenidoğan bebekler ve çocuklar korunması gereken önemli bir popülasyondur. Bu popülasyonun yaşamlarını sağlıklı bir şeklide devamını sağlayabilmek için daha fazla psikolojik, duygusal ve sosyal desteğe ihtiyaçları bulunmakta, bu sebeplerle de kaliteli bir ebelik bakımına gereksinimleri oluşmaktadır (2628). Ebelik hizmetlerinin aksamaması, kadınlara, yeni doğanlara ve çocuklara ulaşımın aksamaması için yaşanan gelişmeler ışığında çeşitli rehberler yayınlanmıştır $(29,30)$. Rehberler ışığında pandemi döneminde ana çocuk sağlığı hizmetlerinin geliştirilmesinde ebelerin rolü; "sağlık hizmetlerine erişim açısından, sağığı korumak ve yükseltmek açısından, kadına yönelik şiddet açısından, doğum hizmetleri açısından, üreme sağıı̆ı ı ve cinsel sağlık açısından, ruh sağlığı açısından ve çocuk sağlığı açısından" ele alınabilmektedir.

Sağlık hizmetlerine erişim açısından; salgın sürecinde ortaya çıkan kısıtlamalarla sağlık kontrollerine erişmek zor olabilmektedir. İçinde bulunduğumuz COVID-19 pandemisi de kadınların rutin sağlık kontrollerine, doğum öncesi ve sonrası kontrollerine, aile planlaması, cinsel ve üreme sağlığı gibi sağlık hizmetlerine erişiminde sıkıntılara neden olmuştur $(9,28,31)$. Bu sıkıntıların başında; kadınların kendilerini pandemi sürecinde enfeksiyon riskini azaltmak ve sosyal izolasyon sağlayabilmek için sağlık kuruluşlarına gitmekten kaçınmaları gelmektedir $(18,30,31)$. Ayrıca pandemi; tedavi, bakım ve danışmanlık gibi sağıı hizmetlerine erişebilmek için kalabalık alanlarda uzun süre beklemek enfeksiyon bulaşma riskini artıracağı düşüncesi nedeniyle sağlık kuruluşuna başvurmayan ve bu hizmete erişemeyen birçok kadında sağlığını tehdit edecek durumlar ortaya çıkmasına ve mevcut hastalıkların ilerlemesine, temel tıbbi hizmetlerin aksamasına neden yol açmıştır (29-31). Ebeler cinsel sağlık ve üreme sağlığı başta olmak üzere tüm sağıık hizmetlerini kadınlar için ücretsiz, güvenilir ve erişilebilir şartlarda sunmalı, güvenli gebelik ve doğum hizmeti, temel ve acil sağlık hizmetlerini 7 gün 24 saat olmasını sağlamalı, verdiği bu güvenli sağlık hizmetlerini sürdürmeli ve hizmete erişebilmeleri noktasında onları desteklemelidir. Hizmet sürekliliğinin ve erişiminin önündeki bilgi eksikliği, kaygı, ulaşım gibi engellere müdahale etmeli, bu engelleri ortadan kaldırmalıdır (1). Yine ebeler başta şiddete maruz kalan veya karantinada şiddete maruz kalma riski bulunanlar olmak üzere kadınların ve kız çocuklarının psiko-sosyal destek hizmetleri de dâhil sağlık hizmetlerine erişebilmelerini sağlamalıdır $(2,16)$.

Sağıı̆ı korumak ve yükseltmek açısından; ebeler pandemi döneminde önce kadınların dolayısıyla onların baktıkları ailelerin sağlıklarını yükseltmek için sağlıklı beslenme, egzersiz, günlük yaşamın dengeli ve stressiz hale getirilmesi, alışkanlık yapan maddelerden kaçınma gibi konuları içeren sağlığın geliştirilmesi çalışmalarında eğitim ve danışmanlık rollerini kullanarak kadınların sağlık bilinci gelişmesine rehberlik etmelidir (18). Ayrıca ebeler toplumun eğitim düzeyinin yükseltilmesi, doğum öncesi bakım, doğum ve sonrasında sağlık hizmetinin nitelik ve niceliğinin yükseltilmesi, aile planlaması hizmetleri ile istenmeyen gebeliklerin önlenmesi, kadın ve çocuk sağlığı izlemlerinin nitelikli ve düzenli yapılması, aşı ile salgından korunma ve pandemi döneminde halkın aşılanması adına mücadele etmelidir $(1,5)$.

Kadına yönelik şiddet açısından; pandemiler dahil olmak üzere olağan üstü olayların yaşandığı durumlarda kadınlara yönelik şiddet kadın sağlığını tehdit etmeye devam etmekte hatta artmaktadır (9). Birleşmiş Milletler pandemi sürerken pek çok ülkede kadınlara ve kız çocuklarına yönelik şiddetin arttığını rapor etmiş ve ev içi şiddet acil yardım hattı ve sığınma evi talebi konusunda artan sayıda yardım çağrıları aldıklarını bildirmiştir (26). Sosyal izolasyon tedbirleri ve karantina ile beraber dünyanın farklı yerlerinden toplumda suç işleme düzeyinin düştüğünü fakat kadın odaklı ev içi şiddet olaylarının arttığını belirten ve bu konuda endişeleri ifade eden haberler ortaya çıkmaya başlamıştır (32). Yapılan araştırmalarda pandemi döneminde erkeklerin daha fazla şiddete başvurduğu belirlenmiş, sokağa çıkma kısıtlamalarının uzun sürmesi durumunda 31 milyon kadına yönelik şiddet olayının ortaya çıkması beklendiği vurgulanmış, Çin'in Jianli 
şehrinde şiddeti vakalarının üç kat arttığını, aile içi şiddet yardım hattına yapılan başvuruların \%48 oranında arttığını belirterek bu konuda endişe duyduklarını dile getirmiş, yapılan başka bir çalışmada katılımcıların çoğunluğunun (kadınların \%71,8'i) ev içi şiddete maruz kaldıkları takdirde nereden yardım ve destek alabileceklerini bilmediklerini belirtmiştir $(25,33)$. Pandemi döneminde karantina nedeniyle kadına yönelik şiddetin arttığı ve kadınların daha fazla sıkıntı yaşamamak için kendinden istenen her şeyi yapmak durumunda kaldığı, birçok ülkede kadın sığınma evlerinin ve cinsel saldırı merkezlerinin sayısının arttığı belirtilmektedir $(5,32)$. Ebeler bu süreçte kadınların şiddet görmesinin engellenmesi ve şiddet gördükleri durumlarda; kadınları Aile, Kadın, Çocuk ve Engelli Sosyal Danışma Hattı (183), Polis İmdat (155), Jandarma İmdat (156), Acil Tıbbi Yardım Hattı (112) gibi telefon numaralarını aramaları konusunda cesaretlendirerek, kadın konukevleri, şiddet önleme ve izleme merkezleri, kadın dayanışma merkezleri ve konukevleri gibi danışmanlık alabileceği merkezler hakkında bilgi sahibi olması, şiddet gören kadın ve çocuklar için acil destek hizmetlerine ulaşabilme ve güvenli sığınma imkanlarının sağlanması, tıbbi, psikolojik ve ekonomik desteklerin ulaştırılması konusunda kadınlara öncülük etmelidir (15).

Doğum hizmetleri açısından amaç; gebelik, doğum ve doğum sonu dönemlerinin sağlıklı geçirilmesini sağlamak, ana ve çocuk sağlığını yükseltmek, özelde aileye genelde topluma sağlıklı bireyler kazandırmaktır $(8,18)$. Pandemi sürecinde gebelerin antenal bakım almalarını engelleyecek bazı faktörler karşımıza çıkmakta olup, bu faktörlerin başında gebe kadınların pandemi sürecinde enfeksiyon riskini azaltmak ve sosyal izolasyon sağlayabilmek için sağlık kuruluşlarına gitmekten kaçınmaları gelmektedir (28,33). Bir taraftan gebeler enfeksiyon riski ile tehlike altında kalmakta bir taraftan da antenatal takiplerin yapılmadığı durumlarda maternal mortalite riskleri artmaktadır (16). Uluslararası Ebeler Derneği ve birçok ebelik dernekleri de düşük riskli gebelerin izlem sayılarının düşmemesi gerektiğini ve tüm gebelerin kaliteli ebelik bakımına ulaşmaları gerektiğini, pandemi süresince gebelerin antenatal takiplerinin yüz yüze, sanal ve evde antenetal ziyaretler ile yapılmasını önermektedir (27). Bu öneriler doğrultusunda doğum öncesi, doğum ve doğum sonu dönemde ebeler anneleri bilgilendirilerek bu dönemlere uyumunu ve sorunların çözümü noktasında onlara yardımcı olmalıdır (3). Pandemi döneminde ebeler enfeksiyon, kanama vb. yönünden risk altında olan annelerin belirlenmesi, hastalık belirtilerinin erken dönemde tespit edilmesi ve gereken önlemlerin alınması, risk taşıyan gebeler gerekli sağlık kurumlarına sevk edilmesi, doğumların sağlıklı koşullarda yapılmasının sağlanması, doğum yapan anne emzirme konusunda cesaretlendirilmesi ve desteklenmesi, doğum sonrasında kendisine en uygun yöntemi seçmesi ve uygulamasını sağlaması konusunda kadınlara her türlü destek ve hizmeti vermelidir $(1,8,16)$.

Üreme sağlığı açısından; pandemiler üreme sağlığını farklı şekillerde etkileyebilir, pandemi sürecinde uygulanan acil müdahaleler üreme sağlığı hizmetleri için ayrılan kaynakların ve çabanın salgınla mücadeleye yönlendirilmesine ve üreme sağlığı hizmetlerinden özellikle doğum kontrol yöntem taleplerinin karşılanamamasına neden olabilir. Örneğin, yayınlanan bir raporda İsviçre, Arnavutluk ve Polonya'da cinsel yolla bulaşan enfeksiyonları önlemek amacıyla verilen danışmanlık, test veya rutin tarama gibi hizmetlerde ciddi bir düşüş gözlemlenmiştir (31). Bütün bunların sonucunda da anne ve bebek ölümlerinde, güvenli olmayan kürtaj ve cinsel yolla bulaşan hastalıklarda, depresyon, intihar ve şiddette artış görülebilir $(31,32)$. Yapılan araştırmalarda yaşadığımız pandemi döneminde aile planlaması hizmetine başvuruların azaldığı, pandemi sürecinde modern aile planlaması kullanımında büyük oranda düşüş olduğu ve aile planlaması danışmanlığında kamu sektöründe, özel sektöre kıyasla daha fazla aksama olduğu belirlenmiştir $(3,9,19)$. Daha önce yaşanılan salgınların sağlıksız ortamlarda düşük yapma, erken doğum, bebekte anomali, istenmeyen gebelikler ve cinsel yolla bulaşan hastalıklarda artış gibi kadınların üreme sağlığını olumsuz etkileyecek sonuçlara neden olduğu belirlenmiştir. Ayrıca geçmişteki dünya çapındaki salgınlarda, kadınların cinsel sağlık ve üreme sağlığı haklarının ebola salgını (2014) sırasında göz ardı edilmesi sonucunda sağlık eşitsizliklerinin ve sosyal adaletsizliklerin şiddetlendiği açıklanmıştır (16,33). Ebeler pandemi sürecinde cinsel sağlık ve üreme sağlığı hizmetlerinin sürekliliğini sağlamalı, bu hizmetlere ulaşamayan kadınlara telefon yada online olarak danışmanlık hizmetlerini ulaştırmalı, aile planlaması yöntemlerinden tek kullanımlıklar yerine uzun dönem kullanıma uygun, ulaşma sorunu yaşamayacakları yöntemlerin (rahim içi araç) kullanımına teşvik etmelidir $(3,24,34)$. Yüksek riskli ya da dezavantajlı kadınlara (göçmen, yaşlı, engelli, gebe ve emziren kadınlara) özel önem vermeli, göçmenlerin dil sorunu nedeniyle yaşadıkları sıkıntıları aşmak için tercüman aracılığıyla iletişim kurup danışmanlık vermeli, ihtiyaçları karşılanmalıdır. Engelli ya da hizmetlere ulaşamayan kadınlar için mobil araçlarla sağlık hizmetini onlara götürmelidir $(1,5)$.

Cinsel sağlık açısından, koronavirüs pandemisinin çok kısa bir zaman diliminde ilerleyişi insanların özgürlükleri kısıtlanmış, maddi ve manevi zarara uğramış ve bu ani değişim insanlar üzerinde korku, panik, anksiyete ve depresyona, gelecek kaygısı ve ne olacağını kestirememek insanlarda çaresizlik ve duygusal dalgalanmalara yol açmıştır (11). Konu ile ilgili 
yapılan çalışmalarda araştırmaya katılanların üçte ikisinin sosyal izolasyon sırasında cinsel olarak aktif olmadığı, dörtte birinin cinsel istekte azalma yaşadığı, yarıya yakınının cinsel partner sayısında azalma olduğu ve erkeklerin kadınlara göre cinsel partner sayısında azalmanın daha düşük olduğu, erkeklerin ve kadınların yaklaşık üçte birinde cinsel tatminde azalma yaşadığı belirlenmiştir (2). Diğer yandan yapılan bazı çalışmalarda pandemi sürecinde sokağa çıkma yasağı ve karantina nedeniyle çiftlerin cinsel ilişkiye ayırdıkları sürenin arttığı bildirilmiştir $(5,13,24)$. Ebeler kadınlardaki korku veya kaygı nedeniyle cinsel işlev bozukluğunun azalması konusunda psikolojik, sosyal ve biyolojik faktörleri araştırmalı, kadınlara destek ve bilgi sağlamalıdır (31).

Ruh sağı̆̆ı açısından; pandemi sürecinde değişikliğe uğrayan aile düzeni, ilişkileri ve rolleri nedeniyle aile üyeleri çeşitli ruhsal sorunlarla karşı karşıya kalabilmekte, aile ilişkileri ve rolleri olumsuz etkilenebilmekte, psikolojik sorunlar ve hastalık belirtileri görülebilmektedir (21,32,33). Yapılan araştırmalarda insanların COVID-19 pandemisinden psikolojik olarak orta/şiddetli olarak etkilendiği, üçte birinde orta/şiddetli anksiyete ve depresyon belirtileri görüldüğü, uyku ve uyum bozuklukları, alkol ve madde kullanımında artma, suçluluk, kaygı, umutsuzluk, tükenmişlik gibi duyguları şiddetli yaşadığı, tamamına yakında COVID- 19 hakkında endişe ve günlük rutinlerinde bozulma yaşandığı bildirmiştir $(16,33)$. Ayrıca pandemi sürecinde bireylerin kaygı düzeylerinin arttığı da çeşitli araştırmalarda ortaya koyulmuştur $(29,30)$. Ebeler pandemiden etkilenen kadınlara, ailelere ve topluluklara psiko-sosyal destek sağlanması ve bu desteğin sürdürülmesi konusunda çalışmalıdır. Wang (2020) tarafından yapılan çalışmada kişilere detaylı, güncel ve doğru sağlık bilgilerinin verilmesinin ve onlara özel, bireysel önlemler alınmasının psikolojik etki, stres, depresyon ve kaygı düzeyinin azalmasını sağladığı gözlemlenmiştir (34). Bunun yanı sıra anne ve çocuklar için pandemiyle mücadele konusunda bilgilendirmeler, aileleri sosyal ve psikolojik açıdan desteklemeye yönelik faaliyetler ve aileler için evdeki zamanı kaliteli geçirmek adına çeşitli öneriler sunmalı ve ailelerin bu süreci en sağlıklı şekilde geçirmeleri ve stres, kaygı ve korkularını en aza indirmeleri için desteklemelidir $(24,32)$.

Çocuklar açısından; COVID-19 enfeksiyonunun genellikle (\%81) asemptomatik veya hafif hastalık (pnömoni yok/hafif pnömoni) şeklinde seyrettiği, vakaların \%14'ünde ağır hastalık (dispne, hipoksi, radyolojik olarak yaygın tutulum) ve $\% 5$ 'inde ise kritik hastalık (organ yetmezliği, şok) görüldüğü belirlenmiştir (35). Ayrıca yaşanan COVID-19 enfeksiyonunun doğrudan etkilerinin yanı sıra hastalığın bulaşmasını önlemeye ve kontrol altına almaya yönelik tedbirler, çocuklar açısından henüz bilemediğimiz riskleri de ortaya çıkartabileceği öngörülmektedir $(5,10,11)$. DSÖ tarafından ilan edildiği 2020 yılının mart ayından bu yana, COVID-19 pandemisi nedeniyle rutin aşı programları aksadığı için, dünyada 80 milyonu aşkın çocuk difteri, kızamık ve çocuk felci gibi bulaşıcı hastalıklara yakalanma riski ile karşı karşıya kaldığı, rutin çocukluk dönemi aşılaması hizmetlerinin tüm dünyada aksadığı bildirilmiştir (31). Bunların yanında pandemi süresince milyonlarca çocuk okula gitmemiş, uzaktan öğrenim görmüş, çocuklar ev içinde daha fazla zaman geçirmiştir. Ev içinde geçirilen zaman artışı çocukların dikey hayattan paralel hayata geçişine neden olmuş, bu da çocuklarda vücut ağırlığında artış, bağışıklık sisteminin baskılanması ve bazı kronik hastalıkların artmasına zemin hazırlamıştır $(17,18)$. Yapılan bir araştırmada enfeksiyonun yayılımının önlenmesi amacıyla, öğretim kurumlarının kapatılması sonucu dünya çapında yaklaşık 1,5 milyar çocuk ve ergenin okula gitmediği, çocuklarda fizik aktivitenin azaldığı ve buna paralel olarak bilgisayar ve internet kullanımının, ekran bağımlılığının arttığı ve bu faktörlerin çocuklarda obezite gelişiminin ve ruh sağlığı problemlerinin ortaya çıkmasına neden olduğu belirtilmiştir (26). Ebeler, çocuklarda bağışıklığın sağlanması, olumsuz çevre koşullarının düzeltilmesi, şiddetin ve yaralanmaların önlenmesi konularında eylem planlarının uygulanması, çocuklara yönelik şiddet uygulamalarının soruşturulması ve bildiriminin yapılması, çocukların sağlık sistemi içinde koruyucu ve geliştirici hizmetlerden yararlanmalarının artırılması, engelli çocukların sağlık hizmetlerine ulaşılabilirliğinin artırılması yönünde çalışmalıdır $(2,5,17,32)$.

\section{Sonuç ve Öneriler}

Koronavirüs pandemi sürecinin ana ve çocuk sağlığı üzerindeki olumsuz etkilerinin oldukça fazla olduğu görülmekte, bu sürecin uluslararası iş birliğiyle küresel olarak ele alınması gerekmektedir. Bu pandemi sürecinin kadın hayatına ve sağlığına getirdiği olumsuz etkiler kadınların birçok yönden daha fazla risk altında olmasına ve birçok kadının ihtiyaç duyduğu desteğe erişememesine neden olmuştur. Kadın sağlığının gelişmesi önce aile daha sonra toplum sağlığının da gelişmesi demektir bu nedenle pandemi sürecinin ana çocuk sağlığına olumsuz etkilerinin belirlenerek, bu etkileri iyileştirme çabalarına hizmet edebilecek önlemlerin alınması oldukça önemlidir. Uluslararası Ebeler Derneği temalarından biri olan "Ebeler ve kadınlar yaşam ortaklarıdır" kavramı pandemi sürecinde ebelerin ne kadar da önemli bir etkisi olduğunu bir kez daha ortaya koymuştur. Ebeler pandemi döneminde ana çocuk sağlığının korunması ve geliştirilmesinde sağlık hizmetlerine erişim, sağlığı korumak ve yükseltmek, üreme sağlığı, kadına yönelik şiddet, doğum hizmetleri, cinsel sağlık, çocuklar ve ruh sağlığı açısından çeşitli 
DEMIR § TAŞPINAR

Pandemi Döneminde Ana Çocuk Sağlığı Hizmetleri

rollerde yer almakta ve toplum tabanlı ebelik hizmetlerini pandemi sürecinde de aksatmadan sürdürmekte, günümüzde pandemi ile mücadelede en önde görevlerini yapmaktadırlar.

\section{Çıkar Çatışması}

Bu yazı tamamı ile bilimsel amaçla yazılmış olup, yazarların bu yazı ile ilgili herhangi bir çıkar çatışması bulunmamaktadır.

\section{Kaynaklar}

1. Taşkın L. Doğum ve kadın sağlığı hemşireliği, 16. baskı, Ankara: Akademisyen Tıp Kitabevi; 2020.

2. Bick D. COVID-19: 2020 Is the international year of the midwife. Midwifery 2020; 85: 102719. https://doi.org/10.1016/j. midw.2020.102719

3. Bertucci V, Boffo M, Mannarini S, et al. Assessing the perception of the childbirth experience in Italian women: A contribution to the adaptation of the childbirth perception questionnaire. Midwifery 2012; 28: 265-274.

4. Rahman A, Surkan PJ, Cayetano CE, Rwagatare P, Dickson KE. Mental health into maternal and child health programmes. Plos Medicine 2013; 10: E1001442.

5. Mert A. COVID-19 salgını sürecinde farklı yönleriyle kadınların durumu. Erişim tarihi 25 Aralık 2020. Erişim adresi: https:// kockam.ku.edu.tr/covid-19-salgini-surecinde-farkli-yonleriylekadinlarin-durumu-asli-e-mert/

6. T.C. Sağlık Bakanlığı. Türkiye'deki güncel durum. Erişim tarihi: 22 Mayıs 2020. Erişim adresi: https://Covıd19. saglik.gov.tr/.

7. Başgöl Ş, Oskay Ü. Ana çocuk sağlığı hizmetlerinin geliştirilmesinde anne dostu hastane modeli. Anadolu Hemşirelik ve Sağlık Bilimleri Dergisi 2014; 17(2): 125-129.

8. Ekti Genç R, Cesur B. Yenidoğan sağlığına giriş. 1. baskı, Elâzığ: 2016.

9. World Health Organization. Rolling updates on coronavirus disease. Erişim tarihi: 9 Mart 2020. Erişim adresi: https://www. who.int/emergencies/diseases/novel-coronavirus-2019/eventsas-they-happen.

10. Liao X, Wang B, Kang Y. Novel coronavirus infection during the 2019-2020 epidemic: preparing intensive care units. The experience in Sichuan province, Chin. Intensive Care Medicine 2020; 46: 35760. doi: 10.1007/s00134-020-05954-2

11. Huang Hc, Wang Sy, Chen Ch. Body image, maternal-fetal attachment, and choice of infant feeding method: A study in Taiwan. Birth 2004; 31: 5-12.
12. Işık K. Koronavirüs ve halk sağ|ı̆̆ı hemşiresinin rolü. Malatya: İnönü Üniversitesi Yayınevi; 2020.

13. Yağmur Y. Covıd-19'un kadın sağlığı üzerine etkileri. Malatya: İnönü Üniversitesi Yayınevi; 2020.

14. United Nations International Children's Emergency Fund. Coronavirus disease (Covid-19): What parents should know. How to protect yourself and your children? 2020 Erişim tarihi: 18 Mayıs 2020. Erişim adresi: https://www.unicef.org/stories/novelcoronavirusoutbreak-what-parents-should-know.

15. Demir R, Taşpınar A. Kadın sağlık çalışanları kalıcı aile planlaması yöntemleri hakkında ne düşünüyorlar? Tek durumlu bir örnek olay çalışması. Anadolu Hemşirelik ve Sağlık Bilimleri Dergisi 2018; 21: 25-32.

16. Renfrew MJ, Cheyne H, Craig J, Duff E, Dykes F, Hunter B, et al. Sustaining quality midwifery care in a pandemic and beyond. Midwifery 2020; 88: 102759.

17. Campbell J, Cometto G, Rasanathan K, Kelley E, Syed S, Zurn P, Nove A. Improving the resilience and workforce of health systems for women's, children's, and adolescents' health. BMJ 2015; 351: H4148.

18. Bhutta ZA, Blac RE. Global maternal, newborn, and child health, so near and yet so far. New England Journal of Medicine 2013; 369(23): 2226-2235.

19. World Health Organization. Global strategy for women's, children's and adolescents' health 2016-2030. Erişim tarihi: 10 Haziran 2021. Erişim adresi: https://apps.who.int/gb/ebwha/ pdf_files/WHA72/A72_30-en.pdf

20. Demir R, Özçırpıcı B. Bir sağlık ocağı bölgesinde yaşayan 0-2 yaş çocuklarda malnütrisyon sıklığı ve malnütrisyon saptanan çocukların annelerine verilen eğitimin etkisi. Çocuk Sağlığı ve Hastalıkları Dergisi 2014; 57: 83-190.

21. Bozkurt G, Erdim L. Türkiye'de anne çocuk sağlığı durumu. HSP 2019; 6: 575-82.

22. T.C. Sağlık Bakanlığı. Türkiye Üreme Sağlığı Programı. Cinsel sağlık ve üreme sağlığı hizmetleri için bir çerçeve. Erişim tarihi: 9 Mart 2020. Erişim adresi: https://dosyamerkez.saglik.gov.tr/ Eklenti/5150,hizmet-cercevesi-dokumanpdf.pdf?0

23. Türkiye İstatistik Kurumu. Erişim tarihi: 9 Mart 2020. Erişim adresi: https://data.tuik.gov.tr/Search/Search?text=anne\%20bebek\%20 \%C3\%B6|\%C3\%BCm\%C3\%BC\&dil=1 
Volume 3 Number 4 p: 104-110

24. Evcili F, Demirel G. COVID-19 pandemisi'nin kadın sağlığına etkileri ve öneriler üzerine bir değerlendirme. Türk Fen ve Sağlık Dergisi 2020; 1: 1-2.

25. United Nations Population Fund (UNFPA). Toplumsal cinsiyet perspektifinden Covid-19. Erişim tarihi 15 Haziran 2020. Erişim adresi: http://www.tapv.org.tr/toplumsal-cinsiyetperspektifinden-covid-19/

26. United Nations (UN). Policy brief: the impact of Covid-19 on women. Erişim tarihi 15 Haziran 2020. Erişim adresi: hhttps://asiapacific. unwomen.org/en/digital-library/publications/2020/04/policybrief-the-impact-ofcovid-19-on-women.

27. International Confederation Midwifery. Women's rights in childbirth must be upheld during the coronavirus pandemic. Erişim Tarihi 10 Mayıs 2020. Erişim adresi: https://www. internationalmidwives.org/assets/files/news-files/2020/03/ icm statement_upholding-womensrights-during-covid195e83ae2ebfe59.pdf

28. Brigante $L$, et al. Information for health care professionals, guidance for provision of midwife-led settings and homebirth in the evolving coronavirus (COVID-19) pandemic. Erişim Tarihi 10 Mayıs 2020. Erişim adresi: https://www.rcm.org.uk/media/4099/2020-05-22guidance-for-provision-of-midwife-led-settings-and-home-birth-inthe-evolving-coronavirus-covid-19-pandemic .pdf
29. Çölgeçen $Y$, Çölgeçen H. Covid-19 pandemisine bağlı yaşanan kaygı düzeylerinin değerlendirilmesi: Türkiye örneği. Turkish Studies 2020; 15: 261-275.

30. Göksu Ö, Kumcağız H. Covid-19 salgınında bireylerde algılanan stres düzeyi ve kaygı düzeyleri. Turkish Studies 2020; 15(4): 463-479.

31. Hussein J. Covid-19: What implications for sexual and reproductive health and rights globally? Sex Reprod Health Matters 2020; 28: 1-4.

32. Toprak Ergönen A, Biçen E, Ersoy G. COVID-19 salgınında ev içi şiddet. Bull Leg Med 2020; 25: 48-57.

33. Roesch E, Amin A, Gupta J, Garcia-Moreno C. Violence against women during COVID-19 pandemic restrictions. BMJ. 2020;369:m1712

34. Wang C, Pan R, Wan X, et al. Immediate psychological responses and associated factors during the initial stage of the 2019 coronavirus disease (COVID-19) Epidemic among the General Population in China. Int J Environ Res Public Health 2020;17:1729.

35. Chan JF, Yuan S, Kok KH, To KK, Chu H, Yang J, et al. A familial cluster of pneumonia associated with the 2019 novel coronavirus indicating person-to-person transmission: A study of a family cluster. Lancet 2020; 395:514-23. 